\title{
ARPP-21, A Cyclic AMP-Regulated Phosphoprotein Enriched in Dopamine-Innervated Brain Regions. I. Amino Acid Sequence of ARPP-21B from Bovine Caudate Nucleus
}

\author{
Kenneth R. Williams, ${ }^{1}$ Hugh C. Hemmings, Jr., ,a Mary B. LoPresti, ${ }^{1}$ and Paul Greengard ${ }^{2}$ \\ 'Department of Molecular Biophysics and Biochemistry, Yale University, New Haven, Connecticut 06510, and 'Laboratory \\ of Molecular and Cellular Neuroscience, The Rockefeller University, New York, New York 10021
}

\begin{abstract}
ARPP-21 (cAMP-regulated phosphoprotein, $M_{r}=21,000$ as determined by SDS-PAGE) is a major cytosolic substrate for cAMP-stimulated protein phosphorylation in dopamine-innervated regions of the rat $\mathrm{CNS}$. It has recently been purified to homogeneity from bovine caudate nucleus and characterized (Hemmings and Greengard, 1989). ARPP-21 is isolated as 2 isoforms, ARPP-21A and ARPP-21B. The amino acid sequence of purified bovine ARPP-21B has now been determined by gas-phase sequencing. The $S-{ }^{14} \mathrm{C}$-carboxymethylated protein was subjected to enzymatic cleavage with trypsin, chymotrypsin, subtilisin, and endoproteinase Lys-C. The resulting peptides were purified by high-performance liquid chromatography, and selected peptides were subjected to amino acid analysis and/or amino acid sequencing by automated Edman degradation. ARPP-21B consists of a single $\mathrm{NH}_{2}$-terminal blocked polypeptide chain of 88 residues, with a calculated molecular mass of $9561 \mathrm{Da}$, including an $\mathrm{NH}_{2}$-terminal acetyl group inferred by deblocking with an acylaminopeptidase. This molecular mass is significantly lower than earlier estimates based on SDS-PAGE or hydrodynamic measurements. The seryl residue phosphorylated by CAMP-dependent protein kinase (Hemmings et al., 1989) is located at position 55 . The molecule contains 1 cysteinyl residue, at position 71 , and contains no methionyl, tyrosyl, phenylalanyl, tryptophanyl, or histidinyl residues. Determination of the primary structure of ARPP-21, one of several phosphoproteins localized to dopaminoceptive neurons in the basal ganglia, provides a framework for further investigations into the molecular mechanisms involved in dopaminergic neurotransmission.
\end{abstract}

The phosphorylation of specific proteins is a prominent molecular mechanism by which a number of neurotransmitter effects are mediated (for review, see Nestler and Greengard, 1984). ARPP-21 (cAMP-regulated phosphoprotein, $M_{r}, 21,000$ ) is a cytosolic neuronal phosphoprotein that was originally identified

\footnotetext{
Received Dec. 7, 1988; revised Apr. 4, 1989; accepted Apr. 10, 1989.

This work was supported by ISPHS grant MH-40899. K.R.W. was supported by USPHS grant GM-31539. We would like to thank Kathy Stone for expert technical assistance and Drs. Wanda Jones and James Manning of The Rockefeller University for carrying out the acylaminopeptidase reactions.

Correspondence should be addressed to Paul Greengard, Box 296, The Rockefeller University, 1230 York Avenue, New York, NY 10021-6399.

a Present address: Department of Anaesthesia, Massachusetts General Hospital, Boston, MA 02114.

Copyright (C) 1989 Society for Neuroscience $0270-6474 / 89 / 103631-07 \$ 02.00 / 0$
}

in dopamine-innervated regions of mammalian brain as a prominent substrate for cAMP-dependent protein kinase (Walaas et al., 1983). The phosphorylation of ARPP-21 is stimulated in intact cells by 8-bromo-cAMP (Girault et al., 1988; Hemmings et al., 1989), forskolin, or vasoactive intestinal peptide (Girault et al., 1988). ARPP-21 has been purified from bovine caudate nucleus and biochemically characterized (Hemmings and Greengard, 1989). It is an acidic protein (pI 4.6) with an apparent $M_{\mathrm{r}}=21,000$ as determined by SDS-PAGE. cAMP-dependent protein kinase phosphorylates a single seryl residue in ARPP-21 with favorable kinctic parametcrs (Hcmmings and Greengard, 1989; Hemmings et al., 1989). The regional distribution of ARPP-21 in rat brain, determined by immunocytochemistry using specific monoclonal antibodies (Ouimet et al., 1989), correlates with the distribution of dopamine-innervated neurons that possess D-1 dopamine receptors. These findings have led to the hypothesis that ARPP-21 mediates some of the physiolugical effects of dopamine and other neurotransmitters acting through cAMP on dopaminoceptive neurons.

A detailed analysis of the structural and biochemical properties of ARPP-21 and other phosphoproteins concentrated in the basal ganglia has been undertaken as an approach to elucidating the molecular mechanisms involved in synaptic transmission and neurotransmitter interactions in the striatum (Hemmings et al., 1987). ARPP-21 is isolated from bovine brain as 2 isoforms (ARPP-21 A and ARPP-21B), which are separable by anion-exchange chromatography. They are present in approximately equal amounts and are indistinguishable by a number of biochemical and immunochemical criteria (Hemmings and Greengard, 1989). The amino acid sequence surrounding the site in ARPP-21B phosphorylated by cAMP-dependent protein kinase was determined recently (Hemmings et al., 1989). In order to further characterize ARPP-21, we have determined its complete amino acid scquence. Bclow, we report the results of the direct amino acid sequencing of bovine brain ARPP-21B. In the accompanying paper, we report the molecular cloning and nucleotide sequence of the cDNA derived from bovine brain ARPP-21 mRNA, which was selected using 2 synthetic oligonucleotide probes based on the amino acid sequence. Determination of the amino acid and nucleotide sequences of ARPP21 provides the basis for detailed studies of the function and regulation of ARPP- 21.

\section{Materials and Methods}

Materials. Unless specified otherwise, materials were as described previously (Williams et al., 1986). ARPP-21A and ARPP-21B were purified from bovine caudate nucleus as described previously (Hemmings and 

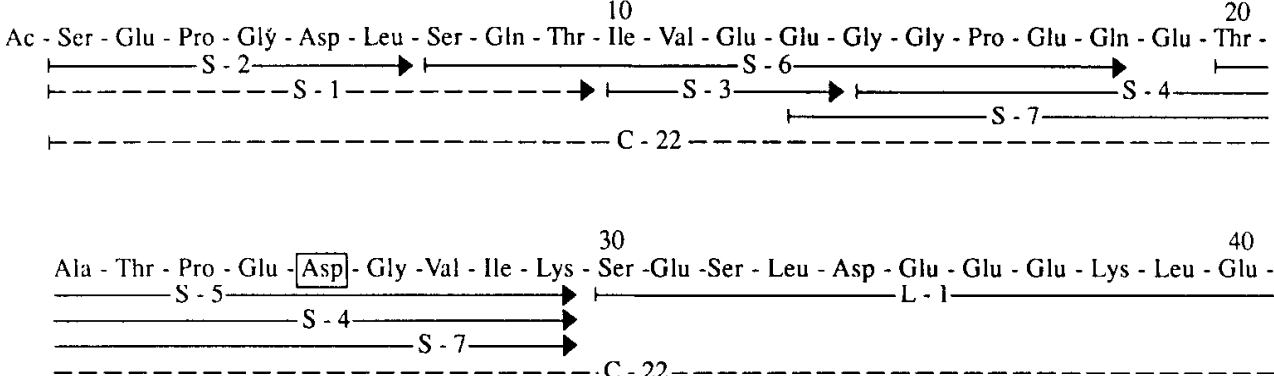

Figure 1. The complete amino acid sequence of bovine ARPP-21B. Solid lines indicate peptides that were sequenced; dashed lines indicate that the amino acid composition of the peptide is consistent with the proposed sequence. The single-headed arrow indicates the last residue that could be sequenced in each peptide, which, because some of the peptides were only partially sequenced, is not necessarily the $\mathrm{COOH}$ terminus of the peptide. Peptides were derived from ARPP-21B by cleavage with chymotrypsin (C), endoproteinase Lys-C $(L)$, subtilisin $(S)$, and trypsin $(T)$. The leftward arrow indicates the residue released by carboxypeptidase $Y$. The box indicates the single difference between the amino acid sequence determined directly and the sequence deduced from the cDNA nucleotide sequence. $P$ indicates the phosphorylatable seryl residue at position 55 .

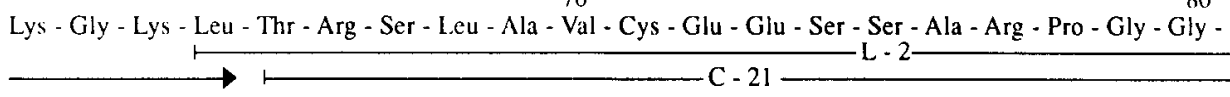

Greengard, 1989); the purified proteins were reduced and S- ${ }^{14} \mathrm{C}-\mathrm{car}-$ boxymethylated as described (Williams et al., 1986), dialysed exten-

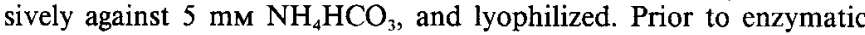
digestion, ARPP-21A and ARPP-21B thus obtained were further purified by reverse-phase high performance liquid chromatography (HPLC) using a Vydac C-18 column as described below for the purification of ARPP-21B peptides.

Enzymatic digestion of ARPP-21. Purified, reduced, and S- ${ }^{14} \mathrm{C}-\mathrm{car}-$ boxymethylated ARPP-21A and ARPP-21B $(0.5 \mathrm{nmol}$ each $)$ were subjected to proteolytic digestion by endoproteinase Lys-C for $24 \mathrm{hr}$ at $37^{\circ} \mathrm{C}$ in $0.2 \mathrm{ml}$ of $25 \mathrm{~mm}$ Tris- $\mathrm{HCl}(\mathrm{pH} 7.6)$ and $2 \mathrm{M}$ urea with a substrate/ enzyme ratio of 400:1 (wt/wt). Proteolytic digestion of $5 \mathrm{nmol} \mathrm{S}-{ }^{14} \mathrm{C}$ carboxymethylated ARPP-21B by endoproteinase Lys-C was carried out for $24 \mathrm{hr}$ at $37^{\circ} \mathrm{C}$ in $0.2 \mathrm{ml}$ of $25 \mathrm{~mm}$ Tris- $\mathrm{HCl}(\mathrm{pH} 7.6)$ and $2 \mathrm{M}$ urea with a substrate/enzyme ratio of $400: 1$ (wt/wt). Proteolytic digestion of $49 \mathrm{nmol} \mathrm{S}-{ }^{14} \mathrm{C}$-carboxymethylated ARPP-21B by TPCKtreated trypsin was carried out for $24 \mathrm{hr}$ at $37^{\circ} \mathrm{C}$ in $25 \mathrm{~mm} \mathrm{NH}_{4} \mathrm{HCO}_{3}$ and $2 \mathrm{M}$ urea with a substrate/enzyme ratio of $25: 1$ (wt/wt). Proteolytic digestion of $22 \mathrm{nmol} \mathrm{S}-{ }^{14} \mathrm{C}$-carboxymethylated ARPP-21B by subtilisin (Sigma, type XXVII) was carried out for $2 \mathrm{hr}$ at $37^{\circ} \mathrm{C}$ in $25 \mathrm{mM} \mathrm{NH}_{4} \mathrm{HCO}_{3}$ and $2 \mathrm{M}$ urea with a substrate/enzyme ratio of $25: 1(\mathrm{wt} / \mathrm{wt})$. The $\mathrm{NH}_{2-}$ terminal blocked tryptic peptide $\mathrm{T}-1(10 \mathrm{nmol})$ was digested by subtilisin for $2 \mathrm{hr}$ at $37^{\circ} \mathrm{C}$ in $25 \mathrm{mM} \mathrm{NH}_{4} \mathrm{HCO}_{3}$ with a substrate/enzyme ratio of $25: 1(\mathrm{wt} / \mathrm{wt})$. The above reactions were terminated by injection of the reaction mixture directly onto an HPLC column. Carboxypeptidase $Y$ digests of $2 \mathrm{nmol}$ aliquots of intact ARPP-21B or purified peptides were carried out for $1 \mathrm{hr}$ at $37^{\circ} \mathrm{C}$ in $0.2 \mathrm{M}$ sodium acetate with a substrate/ enzyme ratio of 100:1 (wt/wt). The reactions were terminated by acidification and injection of the mixture directly onto a Beckman $121 \mathrm{M}$ ion-exchange amino acid analyzer. The $\mathrm{NH}_{2}$-terminal blocked subtilisin peptide S-2 $(0.5 \mathrm{nmol})$ was cleaved with acylaminopeptidase at $\mathrm{pH} 7.5$ for $72 \mathrm{hr}$ at $25^{\circ} \mathrm{C}$ as described (Jones and Manning, 1985; Jones et al., 1986)

Purification and amino acid sequencing of ARPP-21B peptides. Peptides resulting from the enzymatic cleavage of ARPP-21B were separated by reverse-phase HPLC using a Waters Associates HPLC systcm employing a Vydac C-4 or C-18 column $(0.46 \times 25 \mathrm{~cm}, 300 \AA$ pore size, $5 \mu \mathrm{m}$ particle size). The column was equilibrated with $0.05 \%$ (vol $/$ vol) trifluoroacetic acid (buffer A) at a flow rate of $0.7 \mathrm{ml} / \mathrm{min}$, and the peptides were separated by elution with increasing concentrations of buffer B $[0.05 \%(\mathrm{vol} / \mathrm{vol})$ trifluoroacetic acid and $80 \%$ acetonitrile] as follows: 0-90 $\mathrm{min}(0-37.5 \% \mathrm{~B}), 90-135 \mathrm{~min}(37.5-75 \% \mathrm{~B})$. Fractions were collected automatically by peaks as detected by absorbance at 210 $\mathrm{nm}$ using an ISCO model 2150 peak detector. Amino acid analysis was performed following acid hydrolysis and precolumn derivatization with phenylisothiocyanate using a Waters Associates Pico-Tag system (Stone and Williams, 1986). Peptides selected for sequence analysis were subjected to automated gas-phase amino acid sequencing using an Applied Biosystems $470 \mathrm{~A}$ amino acid sequencer as described (Williams et al., 1986).

\section{Results}

\section{General strategy}

Three chymotryptic peptides comprised $95 \%$ of the total amino acid residues of ARPP-21B (Fig. 1). Additional peptides and amino acids needed to complete the sequence were obtained from cleavages made with endoproteinase Lys-C, subtilisin, trypsin, and carboxypeptidase $Y$. The sequence of the blocked $\mathrm{NH}_{2}$-terminal residue was determined using an acylaminopeptidase. Approximately $2 \mathrm{mg}$ purified ARPP-21B were used in the sequence determination.

\section{Analysis of purified ARPP-21 by HPLC}

Purified, reduced, and S-carboxymethylated ARPP-21A and ARPP-21B were analyzed by HPLC as shown in Figure 2. Both proteins were homogeneous as analyzed by SDS-PAGE (Fig. 7 in Hemmings and Greengard, 1989). ARPP-21B was also essentially homogeneous as analyzed by reverse-phase HPLC. However, ARPP-21A was resolved into 2 major peaks by reverse-phase HPLC. A comparison of the later-eluting ARPP$21 \mathrm{~A}$ peak and ARPP-21B purified by HPLC by analytical reverse-phase HPLC peptide mapping following digestion by endoproteinase Lys-C is shown in Figure 3. A major triplet of peptides eluting near $62 \mathrm{~min}$ is present in both digests; however, 


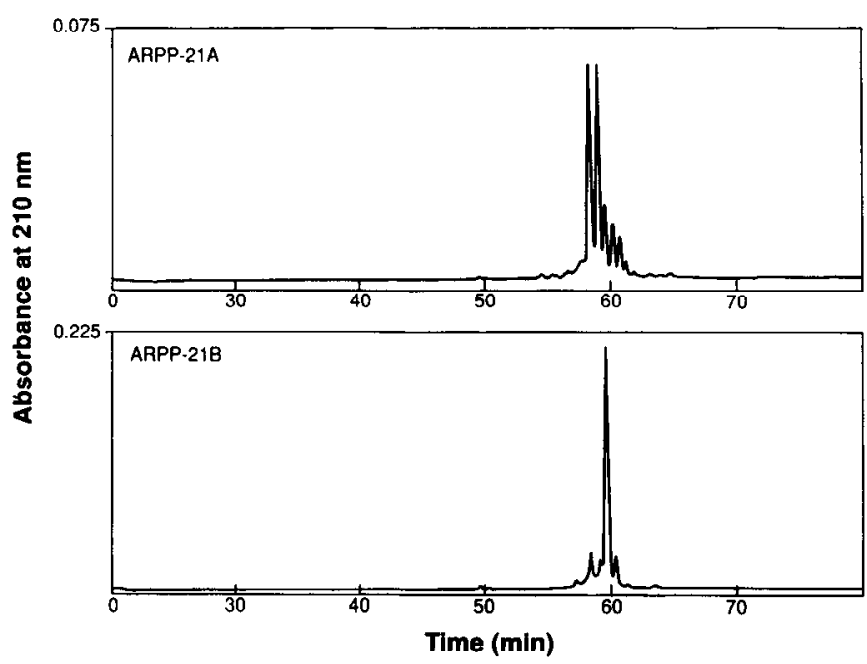

Figure 2. Reverse-phase HPLC chromatograms of purified S-carboxymethylated ARPP-21A (upper) and ARPP-21B (lower) from bovine caudate nucleus. $0.5 \mathrm{nmol}$ of each protein was applied to a $\mathrm{C}-18$ column equilibrated in $0.05 \%(\mathrm{vol} / \mathrm{vol})$ trifluoroacetic acid, which was then eluted with increasing concentrations of acetonitrile as described in Materials and Methods.

the later-eluting peptides of each ARPP-21 isoform appear distinct, suggesting structural heterogeneity between ARPP-21A and ARPP-21B. Heterogeneity between the 2 major peaks of ARPP-21A separated by reverse-phase HPLC (Fig. 2) was also detected by HPLC peptide mapping (data not shown). Given this heterogeneity of purified ARPP-21A, ARPP-21B was chosen for sequence analysis.

\section{Proteolytic cleavage of ARPP-21B with chymotrypsin or endoproteinase Lys- $C$}

The separation HPLC of chymotryptic peptides derived from 24 nmol [ $\left.{ }^{32} \mathrm{P}\right]$ phospho-ARPP-21B is shown in Figure 5 of Hem-

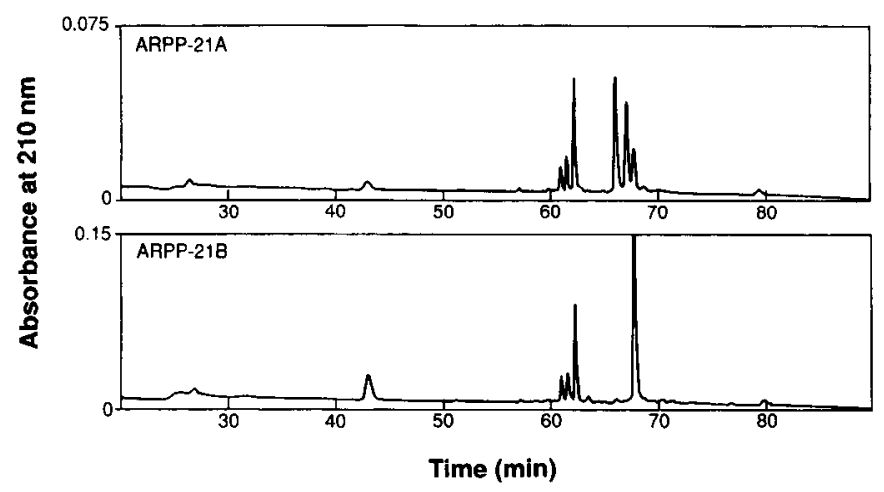

Figure 3. Reverse-phase HPLC chromatograms of peptides from endoproteinase Lys-C digests of the 2 ARPP- 21 isoforms. About $0.5 \mathrm{nmol}$ each of ARPP-21A (reverse-phase HPLC purified; the second major peak obtained in Fig. 2) or ARPP-21B (reverse-phase HPLC purified, see Fig. 2) was digested and the resulting peptides separated by HPLC on a C-18 column equilibrated in $0.05 \%$ (vol $/ \mathrm{vol}$ ) trifluoroacetic acid and eluted with increasing concentrations of acetonitrile as described in Materials and Methods.

mings et al. (1989). The amino acid sequence of residues $46-$ 64 of ARPP-21 B (peptide C-18; Table 1, Fig. 1) was determined in the course of analyzing the phosphorylation site sequence of ARPP-21B (Hemmings et al., 1989). Two other chymotryptic peptides resulting from this digest were useful in establishing the complete sequence of ARPP-21B. Peptides C-21 and C-22 (eluting at 64 and $86 \mathrm{~min}$, respectively, in figure 5 of Hemmings et al., 1989), together with peptide C-18, comprised 84 of the 88 total amino acids of ARPP-21B (Fig. 1). Both intact ARPP$21 \mathrm{~B}$ and peptide $\mathrm{C}-22$ failed to sequence (data not shown), indicating that ARPP-21B has a blocked $\mathrm{NH}_{2}$-terminus and that peptide C-22 represents the $\mathrm{NH}_{2}$-terminus of ARPP-21B. Although peptide C-22 did not yield to direct amino acid sequencing, its amino acid composition was useful in confirming the

\begin{tabular}{|c|c|c|c|c|c|c|c|c|c|c|c|}
\hline Amino acid & $\mathrm{C}-22$ & $\mathrm{C}-18$ & $\mathrm{C}-21$ & $\mathrm{~T}-1$ & $\mathrm{~T}-2$ & $\mathrm{~T}-3$ & $T-4$ & $\mathrm{~T}-5$ & $T-6$ & $\mathrm{~T}-7$ & T-8 \\
\hline Cys & & & ND (1) & & & & & & $0.4(1)$ & ND (1) & \\
\hline Asp & $3.1(3)$ & $1.0(1)$ & $1.1(1)$ & $2.1(2)$ & $1.0(1)$ & $1.1(1)$ & $1.0(1)$ & & & $1.0(1)$ & $1.0(1)$ \\
\hline Thr & $2.9(3)$ & & $1.9(2)$ & $3.0(3)$ & & & & $0.9(1)$ & & $1.0(1)$ & $0.8(1)$ \\
\hline Ser & $3.7(4)$ & $1.6(2)$ & $3.7(4)$ & $2.0(2)$ & $1.9(2)$ & & & & $2.8(3)$ & $3.6(4)$ & $1.1(1)$ \\
\hline Glu & $13.8(13)$ & $3.2(3)$ & $5.3(5)$ & $8.4(8)$ & $6.0(6)$ & $3.2(3)$ & $3.0(3)$ & & $2.3(2)$ & $5.1(5)$ & $3.0(3)$ \\
\hline Pro & $3.0(3)$ & & $0.9(1)$ & $3.1(3)$ & & & & & & $1.0(1)$ & $1.0(1)$ \\
\hline Gly & $4.3(4)$ & $2.9(3)$ & $2.2(2)$ & $4.3(4)$ & & & & & & $2.1(2)$ & $2.1(2)$ \\
\hline Ala & $1.1(1)$ & $1.9(2)$ & $2.0(2)$ & $1.1(1)$ & & $1.0(1)$ & $1.0(1)$ & & $2.2(2)$ & $2.0(2)$ & \\
\hline Val & $2.0(2)$ & $0.9(1)$ & $1.1(1)$ & $1.5(2)$ & & $1.0(1)$ & $1.0(1)$ & & $1.0(1)$ & $1.0(1)$ & \\
\hline \multicolumn{12}{|l|}{ Met } \\
\hline Ile & $1.4(2)$ & & & $1.4(2)$ & & & & & & & \\
\hline Leu & $3.9(4)$ & $1.2(1)$ & $3.0(3)$ & $1.0(1)$ & $3.0(3)$ & $1.0(1)$ & $1.0(1)$ & $1.0(1)$ & $1.1(1)$ & $3.0(3)$ & $1.8(2)$ \\
\hline \multicolumn{12}{|l|}{ Tyr } \\
\hline \multicolumn{12}{|l|}{ Phe } \\
\hline \multicolumn{12}{|l|}{ His } \\
\hline Lys & $1.7(2)$ & $3.8(4)$ & & $1.0(1)$ & $1.0(1)$ & & & & & & \\
\hline Arg & & $2.4(2)$ & $2.0(2)$ & & $1.0(1)$ & $2.0(2)$ & $1.1(1)$ & $1.0(1)$ & $1.0(1)$ & $1.0(1)$ & \\
\hline \multicolumn{12}{|l|}{ Trp } \\
\hline Yield (\%) & 32 & 30 & 17 & 57 & 28 & 8 & 47 & 57 & 6 & 40 & 6 \\
\hline Residues & $1-41$ & $46-64$ & $65-88$ & $1-29$ & $30-43$ & $45-53$ & $45-52$ & 64-66 & $67-77$ & $67-88$ & $78-88$ \\
\hline
\end{tabular}

${ }^{a}$ Determined by ion-exchange amino acid analysis as described under Materials and Methods. Values are expressed as residues per molecule. Values in parentheses are residues per molecule as determined from the sequence. $N D$, not determined. 


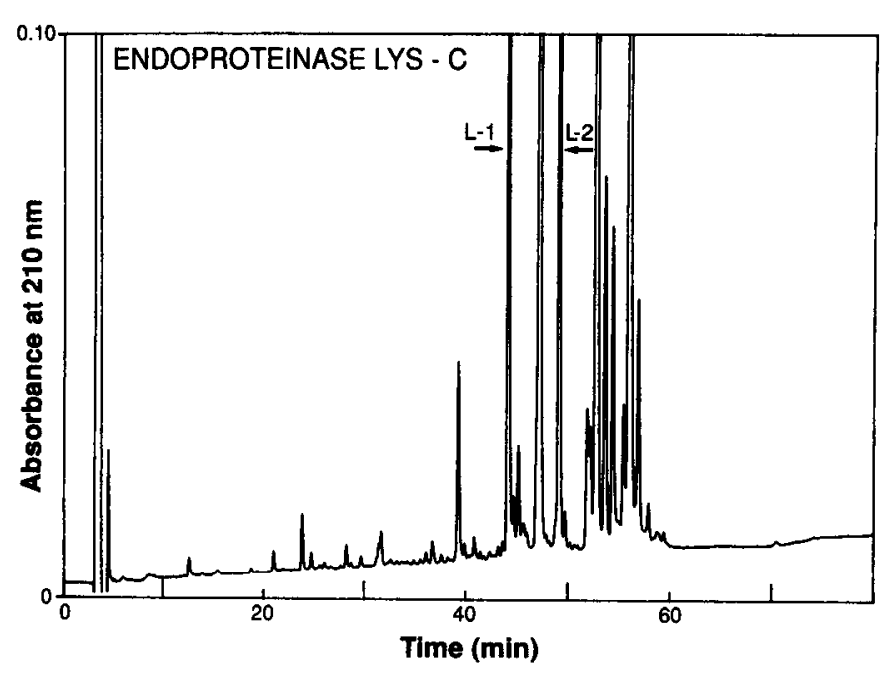

Figure 4. Reverse-phase HPLC chromatogram of peptides from endoproteinase Lys-C digest of $5 \mathrm{nmol}$ of S-carboxymethylated ARPP$21 \mathrm{~B}$. The C- 18 column was equilibrated with $0.05 \%$ (vol $/ \mathrm{vol}$ ) trifluoroacetic acid and eluted with increasing concentrations of acetonitrile as described in Materials and Methods.

sequence of the first 41 amino acids of ARPP-21B. Peptide C-22 also provided an "overlap" for peptides S-4 and L-1 (Fig. 1), which had to be ordered based on its amino acid composition. In the absence of an overlapping sequence, the amino acid composition of peptide $\mathrm{C}-22$ confirmed the proposed ordering of peptides S- 4 and L-1 and strongly suggested that there were no interposed peptides.

Peptide C- 18 contains the single phosphorylation site of ARPP21 B (serine-55, Hemmings et al., 1989), while peptide C-21 contains the only cysteinyl residue in ARPP-21B (Fig. 1). The identification of residue 71 as cysteine was based on the appearance of the characteristic phenylthiohydantoin derivatives of ${ }^{14} \mathrm{C}$-carboxymethylcysteine at the seventh cycle in the sequence of peptide $\mathrm{C}-21$ and was confirmed by a peak of radioactivity at the same cycle (radioactivity at cycles 69, 70, 71, and 72 was $59,53,128$, and $47 \mathrm{cpm}$, respectively). Although peptide C-21 could not be completely sequenced, its amino acid composition is consistent with the proposed $\mathrm{COOH}$-terminal sequence of ARPP-21B.

The preparative separation by HPLC of the peptides resulting from the digestion of $5 \mathrm{nmol}$ ARPP-21 B by endoproteinase Lys$C$ is shown in Figure 4. The differences between the peptide elution pattern shown in Figure 4 and that shown in Figure 3 are probably due to the 10 -fold difference in reactant concentrations. Two peptides from this digest were useful in overlapping the 3 chymotryptic peptides described above; peptide L-1 overlapped peptides C-22 and C-18, while peptide L-2 overlapped peptides C-18 and C-21 (Fig. 1). Peptide L-1 was sequenced completely, while peptide L-2 sequenced to threonine87 , the penultimate amino acid of this peptide and of intact ARPP-21B.

\section{Proteolytic cleavage of $A R P P-21 B$ with trypsin and analysis of} the COOH-terminus

The separation by HPLC of the peptides resulting from the digestion of $49 \mathrm{nmol}$ ARPP-21B by trypsin is shown in Figure 5. Eight of the tryptic peptides isolated appeared to be essentially pure as judged by their amino acid compositions (Table 1). In

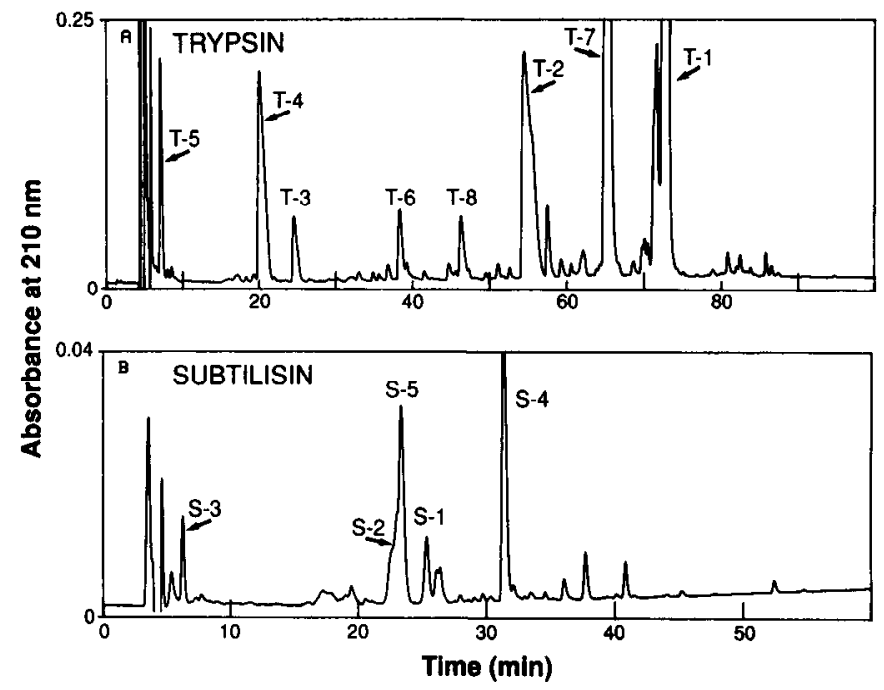

Figure 5. Reverse-phase HPLC chromatograms of peptides from trypsin digest of $49 \mathrm{nmol}$ S-carboxymethylated ARPP-21 B (upper) and subtilisin digest of $10 \mathrm{nmol}$ of peptide T-1 (lower). For each separation, a C-4 column was equilibrated with $0.05 \%(\mathrm{vol} / \mathrm{vol})$ trifluoroacetic acid and eluted with increasing concentrations of acetonitrile as described in Materials and Methods.

all cases, their compositions agreed with the proposed sequence of ARPP-21B (Fig. 1). In particular, the composition of peptide $\mathrm{T}-8$ confirmed the presence of leucine as the $\mathrm{COOH}$-terminal residue of ARPP-21B. This conclusion was verified by carboxypeptidase $Y$ digestion of both intact ARPP-21B and peptide T-8. Under the conditions used, leucine release corresponded to an overall yield approaching 100\% for ARPP-21B and 75\% for peptide T-8. In addition, carboxypeptidase $Y$ digestion of peptide T-8 released 2 or more of the following amino acids which are incompletely resolved under the normal conditions used for ion-exchange chromatography: threonine, serine, glutamine, and/or asparagine.

Proteolytic cleavage of ARPP- $21 B$ with subtilisin and analysis of the $\mathrm{NH}_{2}$-terminus

The amino acid composition of peptide $\mathrm{T}-1$ was consistent with its assignment as the $\mathrm{NH}_{2}$-terminal tryptic peptide of ARPP21B (Table 1). This was supported by its failure to sequence, indicating the presence of a blocked $\mathrm{NH}_{2}$-terminal residue. Several attempts were made to further cleave the blocked peptide $\mathrm{T}-1$. Despite the presence of potential cleavage sites, thermolysin, $S$. aureus V8 protease, and proteinase A each failed to cleave peptide $\mathrm{T}-1$. In contrast, subtilisin proved to be extremely effective. The separation by HPLC of the peptides resulting from the digestion of peptide T-1 by subtilisin is shown in Figure 5. Three of the resulting peptides (S-3, S-4, and S-5) were sequenced (Fig. 1), and the amino acid compositions of the 2 remaining peptides (S-1 and S-2; Table 2) were in agreement with the proposed scquencc of ARPP-21B (Fig. 1). Peptides S-1 and $\mathrm{S}-2$ both failed to sequence, confirming their placement at the $\mathrm{NH}_{2}$-terminus of ARPP-21B.

The $\mathrm{NH}_{2}$-terminal sequence of ARPP-21B was investigated further by analyzing a subtilisin digest of intact ARPP-21B. The separation by HPLC of the peptides resulting from this digest is shown in Figure 6. Additional peptide S-2 was obtained, and $0.5 \mathrm{nmol}$ of this peptide was treated with an acylaminopeptidase (Jones et al., 1986) prior to sequencing. Based on the first cycle 


\begin{tabular}{|c|c|c|c|c|c|}
\hline Amino acid & $\mathrm{S}-1$ & $\mathrm{~S}-2$ & $S-3$ & S-4 & S-5 \\
\hline Asp & $0.9(1)$ & $0.9(1)$ & & $1.2(1)$ & $1.1(1)$ \\
\hline Thr & $0.9(1)$ & & & $2.6(3)$ & $2.0(2)$ \\
\hline Ser & $1.8(2)$ & $1.0(1)$ & & & \\
\hline Gilu & $1.9(2)$ & $1.0(1)$ & $2.5(2)$ & $5.4(5)$ & $1.3(1)$ \\
\hline Pro & $1.1(1)$ & $1.2(1)$ & & $2.9(3)$ & $1.4(1)$ \\
\hline Gly & $1.3(1)$ & $1.2(1)$ & & $4.2(4)$ & $1.3(1)$ \\
\hline Ala & & & & $1.2(1)$ & $0.9(1)$ \\
\hline Val & & & $0.7(1)$ & $0.7(1)$ & $0.5(1)$ \\
\hline \multicolumn{6}{|l|}{ Met } \\
\hline Ile & & & $0.8(1)$ & $0.7(1)$ & $0.5(1)$ \\
\hline Leu & $0.7(1)$ & $0.8(1)$ & & & \\
\hline \multicolumn{6}{|l|}{ Tyr } \\
\hline \multicolumn{6}{|l|}{ Phe } \\
\hline \multicolumn{6}{|l|}{ His } \\
\hline \multicolumn{6}{|l|}{ Arg } \\
\hline \multicolumn{6}{|l|}{$\operatorname{Trp}$} \\
\hline Yield (\%) & 5 & 14 & 5 & 9 & 9 \\
\hline Residues & $1-9$ & $1-6$ & $10-13$ & $14-29$ & $20-29$ \\
\hline
\end{tabular}

" Determined by analysis of phenylthiocarbamyl derivatives as described under Materials and Methods. Values are expressed as residues per molecule. Values in parentheses are residues per molecule as determined from the sequence.

yield of the phenylthiohydantoin derivative of glutamic acid, this enzyme hydrolyzed approximately $5 \%$ of peptide S- 2 . As a result, the sequence of residucs 2-6 could be determined directly. Based on the amino acid composition of peptide S-2 and the known specificity of the acylaminopeptidase, the first residue was inferred to be $N$-acetylserine. The ordering of peptides $\mathrm{S}-2$ and S-6 and the lack of any intervening residues were confirmed by the amino acid composition of peptide S-1 (Table 2, Fig. 1).

The peptide peak labeled S-5, S-6 in Figure 6 was also subjected to amino acid sequencing. This peak contained 2 peptides in approximately equimolar amounts corresponding to residues 7-18 (peptide S-6) and 20-29 (peptide S-5). Peptide S-6 provided an overlap for peptides S-3 and S-4. The sequences of peptides S-4 and S-5, along with that of peptide S-7, provided 3 independent determinations of residue 25 as aspartic acid, the only residue for which there is disagreement between the directly determined amino acid sequence of ARPP-21B and the sequence derived from analysis of the ARPP-21 cDNA (Kurihara et al., 1989). Based on sequence analysis of the ARPP-21 cDNA, residue 25 was identified as asparagine.

As shown in Table 3, the amino acid composition of ARPP$21 \mathrm{~B}$ predicted by the proposed sequence (Fig. 1) is in excellent agreement with the composition determined by ion-exchange amino acid analysis.

\section{Discussion}

ARPP-21 consists of 2 very similar isoforms, ARPP-21A and ARPP-21 B; the complete amino acid sequence of bovine ARPP$21 \mathrm{~B}$ has now been determined by direct sequencing techniques. ARPP-21B is composed of a single polypeptide chain of 88 residues with a blocked $\mathrm{NH}_{2}$-terminus. The $\mathrm{NH}_{2}$-terminal blocking group is inferred to be acetyl based on the substrate specificity of the acylaminopeptidase used for deblocking (Jones and Manning, 1985); $N^{\alpha}$-acetylserine is one of the most fre-

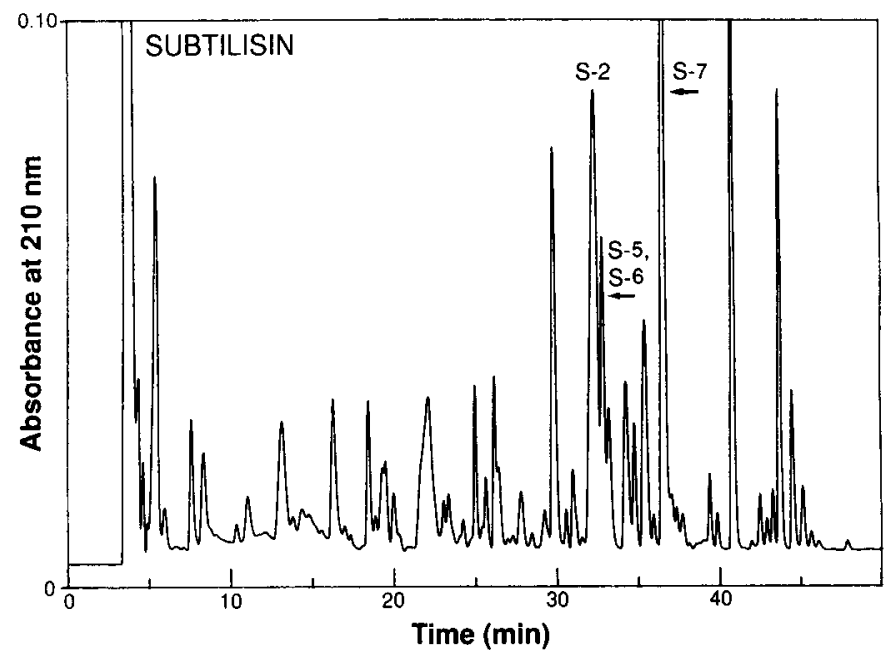

Figure 6. Reverse-phase HPLC chromatogram of peptides from subtilisin digest of $22 \mathrm{nmol} \mathrm{S}$-carboxymethylated ARPP-21B. The C-18 column was equilibrated with $0.05 \%$ (vol/vol) trifluoroacetic acid and eluted with increasing concentrations of acetonitrile as described in Materials and Methods.

quently observed $\mathrm{NH}_{2}$-terminal residues of blocked proteins (Boissel et al., 1985). The molecular mass of ARPP-21B calculated from the amino acid sequence, assuming the $\mathrm{NH}_{2}$-terminus is acetylated, is $9561 \mathrm{Da}$. This value is considerably less than the $M_{r}$ of 21,000 determined by SDS/PAGE (Hemmings and Greengard, 1989). Anomalously slow migration in SDSPAGE appears to correlate with a relative decrease in SDS binding and an extended conformation (Tung and Knight, 1972) and has been observed for other low-molecular-weight, acidic phos-

\section{Table 3. Experimentally determined amino acid composition of ARPP-21B compared with that predicted by the proposed amino acid sequence $^{a}$}

\begin{tabular}{lcc} 
Amino acid & Determined & Predicted \\
\hline Cys & $0.54^{h}$ & $(1)$ \\
Asx & 5.2 & $(5)$ \\
Thr & 4.8 & $(5)$ \\
Ser & 8.8 & $(10)$ \\
Glx & 22.6 & $(22)$ \\
Pro & 4.3 & $(4)$ \\
Gly & 9.2 & $(9)$ \\
Ala & 5.6 & $(5)$ \\
Val & 3.7 & $(4)$ \\
Met & 0 & $(0)$ \\
Ile & 1.6 & $(2)$ \\
Leu & 9.1 & $(9)$ \\
Tyr & 0 & $(0)$ \\
Phe & 0 & $(0)$ \\
His & 0 & $(0)$ \\
Lys & 6.1 & $(6)$ \\
Arg & 6.7 & $(6)$ \\
Trp & 0 & $(0)$ \\
Total & 88.24 & 88
\end{tabular}

Determined by ion-exchange amino acid analysis as described under Materials and Methods. Values are expressed as residues per molecule based on a molecular weight of 9,561 .

"Determined as cysteic acid after performic acid oxidation. 


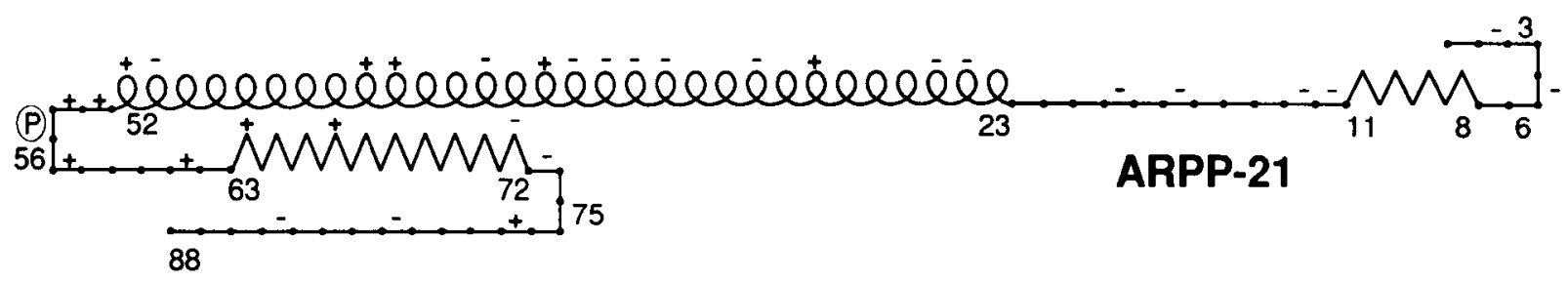

Figure 7. Schematic diagram of the predicted secondary structure of ARPP-21. The prediction was generated by a computer program based on the method of Garnier et al. (1978). Residues are depicted in $\alpha$-helical (loop pattern), $\beta$-sheet (sawtooth pattern), and random coil (straight line) conformations. $\beta$-Turns are indicated by chain reversals. Charged residues are indicated by a + or - , and conformational boundary residues are numbered. The site of phosphorylation is indicated by $P$.

phoproteins including inhibitor-1 (Aitken et al., 1982) and DARPP-32 (Williams et al., 1986).

The amino acid compositions obtained from acid hydrolysates of intact ARPP-21B (Table 3, and Hemmings and Greengard, 1989) are in excellent agreement with that predicted from the amino acid sequence. As noted previously (Hemmings and Greengard, 1989) and confirmed herein, ARPP-21B is devoid of tyrosinyl, phenylalanyl, tryptophanyl, histidinyl, and methionyl residues; there is a single cysteinyl residue at position 71. ARPP-21B consists of $25 \mathrm{~mol} \%$ glutamyl residues, a finding consistent with its low $\mathrm{pI}$. The single seryl residue phosphorylated by cAMP-dependent protein kinase in vitro and by a cAMP analog in intact cells (Hemmings et al., 1989) is located at position 55; the amino acid sequence around serine- 55 conforms to the general specificity requirements for phosphorylation by cAMP-dependent protein kinase (-Arg-Arg-X-Ser-). Based on the amino acid scquence of ARPP-21B and the substrate specificity requirements of casein kinase II (Kuenzel et al., 1987), serine-32 is a potential phosphorylation site for casein kinase II; however, significant phosphorylation of ARPP-21B by this protein kinase does not occur (J.-A. Girault, H. C. Hemmings, Jr., and P. Greengard, unpublished observations).

The amino acid sequence of bovine ARPP-21B determined directly agrees with that deduced from the nucleotide sequence of a cDNA clone derived from bovine ARPP-21 mRNA except for the $\mathrm{NH}_{2}$-terminal residue and position-25 (Kurihara et al., 1989). The differences detected between the amino acid and nucleotide sequences of ARPP-21 demonstrate the need for sequencing at both the polypeptide and polynucleotide levels. Both differences could result from posttranslational modification of ARPP-21B, i.e., by aminopeptidase cleavage of the $\mathrm{NH}_{2}$ terminal initiator methionyl residue in the nascent protein (Yoshida and Lin, 1972) or removal of an $N^{\alpha}$-acetylmethionyl residue by an acetylaminoacylhyrolase (Wold, 1984) and by chemical deamidation of an asparaginyl residue at position 25 , either in vivo or during purification and sequencing. In fact, an $\mathrm{NH}_{2}$-terminal initiator methionyl residue appears to be preferentially cleaved when followed by a seryl (as in ARPP-21B), alanyl, glycyl, or valinyl residue (Boissel et al., 1985), and retained when followed by a charged residue [cf. DARPP-32, in which the preserved initiator methionyl residue is followed by an aspartyl residue (Williams et al., 1986; Kurihara et al., 1988)].

The differences observed between the amino acid and nucleotide sequences of ARPP-21 may also be related to the biochemical heterogeneity of ARPP-21 (Hemmings and Greengard, 1989). Thus, separate mRNA species derived from distinct genes could code for the 2 isoforms (ARPP-21A and ARPP$21 \mathrm{~B}$ ) identified in bovine brain (Hemmings and Greengard,
1989). If so, the ARPP-21 cDNA sequence determined by Kurihara et al. (1989), which contains an asparagine at position 25, might be derived from ARPP-21A mRNA, while the amino acid sequence was determined using purified ARPP-21B. Such a difference between ARPP-21A and ARPP-21B would be consistent with their elution from anion-exchange resins in which ARPP-21 A elutes earlier and is therefore less acidic. However, it is unlikely that the 2 mRNA species identified for ARPP-21 represent separate messages for ARPP-21A and ARPP-21B as discussed in the accompanying paper (Kurihara et al., 1989). Determination of the structural difference between ARPP-21A and ARPP-21B will require direct amino acid sequencing studies of ARPP-21A.

Comparison of the amino acid sequence of ARPP-21B with the sequences in the Protein Sequence Database (5407 sequences, Release 17.0) and the New Sequences in Preparation Database (3181 sequences, Release 35.0) of the Protein Identification Resource using a computer-based survey revealed no significant similarities with other sequences (no initial sequence similarity score $>52$ ). In particular, there was no similarity between the amino acid sequences of ARPP-21B and DARPP32 (Williams et al., 1986), another cAMP-regulated phosphoprotein which is enriched in dopamine-innervated brain regions (Hemmings el al., 1984; Ouimet et al., 1984; Walaas and Greengard, 1984; Hemmings and Greengard, 1986).

The predicted secondary structure of ARPP-21 is shown in Figure 7. Consistent with hydrodynamic studies (Hemmings and Greengard, 1989), ARPP-21 is predicted to have an extended conformation. The phosphorylation site (Ser-55) is located within a $\beta$-turn, a structural feature of a number of substrates for cAMP-dependent protein kinase (Small et al., 1977; Matsuo et al., 1978), including DARPP-32 (Williams et al., 1986). An important role for secondary structural features in the phosphorylation of ARPP-21 by CAMP-dependent protein kinase is suggested by a study of the phosphorylation of a synthetic peptide containing residues 49-61 of ARPP-21. This peptide, which does not include the predicted $\alpha$-helix and $\beta$-sheet structures which flank the phosphorylation site, has a 50 -fold higher apparent $\mathrm{K}_{m}$ value than intact ARPP-21B, possibly due to the absence of a $\beta$-turn.

The function of ARPP-21 is unknown. Its interesting regional distribution in the rat CNS (Ouimet et al., 1989) and the regulation of its state of phosphorylation in intact neurons by a cAMP analog, forskolin, or vasoactive intestinal peptide ( $\mathrm{Gi}$ rault et al., 1988; Hemmings et al., 1989) suggest a role as an intracellular messenger involved in signal transduction in a specific subset of neurons related to the dopamine system. The determination of the primary structure of ARPP-21 and its 
cDNA (Kurihara et al., 1989) will allow further studies of the role of this phosphoprotein in signal transduction by a number of powerful techniques, including the biochemical analysis of synthetic peptides based on the complete amino acid sequence, the production of phosphorylation-state-specific antibodies to synthctic phosphopeptides, site-directed mutagenesis, and in situ hybridization.

\section{References}

Aitken, A., T. Bilham, and P. Cohen (1982) Complete primary structure of protein phosphatase inhibitor-1 from rabbit skeletal muscle. Eur. J. Biochem. 126: 235-246.

Boissel, J.-P., T. J. Kasper, S. C. Shah, J. I. Malone, and H. F. Bunn (1985) Amino-terminal processing of proteins: Hemoglobin South Florida, a variant with retention of initiator methionine and $\mathrm{N}^{\alpha_{-}}$ acetylation. Proc. Natl. Acad. Sci. USA 82: 8448-8452.

Garnier, J., D. J. Osguthorpe, and B. Robson (1978) Analysis of the accuracy and implications of simple methods for predicting the secondary structure of globular proteins. J. Mol. Biol. 120: 97-120.

Girault, J.-A., I. A. Shalaby, N. L. Rosen, and P. Greengard (1988) Regulation by cAMP and vasoactive intestinal peptide of phosphorylation of specific proteins in striatal cells in culture. Proc. Natl. Acad. Sci. USA 85: 7790-7794.

Hemmings, H. C., Jr., and P. Greengard (1986) DARPP-32, a dopamine- and adenosine $3^{\prime}: 5^{\prime}$-monophosphate-regulated phosphoprotein: Regional, tissue and phylogenetic distribution. J. Neurosci. 6: 1469-1481.

Hemmings, H. C., Jr., and P. Greengard (1989) AKPP-21, a cyclic AMP-regulated phosphoprotein enriched in dopamine innervated brain regions. I, Purification and characterization of the protein from bovine caudate nucleus. J. Neurosci. 9: 851-864.

Hemmings, H. C., Jr., A. C. Nairn, D. W. Aswad, and P. Greengard (1984) DARPP-32, a dopamine- and adenosine $3^{\prime}: 5^{\prime}$-monophosphate-regulated phosphoprotein enriched in dopamine-innervated brain regions. II. Purification and characterization of the phosphoprotein from bovine caudate nucleus. J. Neurosci. 4: 99-110.

Hemmings, H. C., Jr., S. I. Walaas, C. C. Ouimet, and P. Greengard (1987) Dopaminergic regulation of protein phosphorylation in the striatum: DARPP-32. Trends Neurosci. 10: 377-383.

Hemmings, H. C., Jr., J.-A. Girault, K. R. Williams, M. B. LoPresti, and P. Greengard (1989) ARPP-21, a cyclic AMP-regulated phosphoprotein enriched in dopamine-innervated brain regions: Amino acid sequence of the site phosphorylated by cyclic AMP in intact cells, and kinetic studies of its phosphorylation in vitro. J. Biol. Chem. 264. 7726-7733.

Jones, W. M., and J. M. Manning (1985) Acylpeptide hydrolase activity from erythrocytes. Biochem. Biophys. Res. Commun. 126:933940.

Jones, W. M., L. R. Manning, and J. M. Manning (1986) Enzymic cleavage of the blocked amino terminal residues of peptides. Biochem. Biophys. Res. Commun. 139: 244-250.
Kuenzel, E. A., J. A. Mulligan, J. Sommercorn, and E. G. Krebs (1987) Substrate specificity determinants for casein kinase II as deduced from studies with synthetic peptides. J. Biol. Chem. 262: 9136-9140.

Kurihara, T., R. M. Lewis, J. Eisler, and P. Greengard (1988) Cloning of cDNA for DARPP-32, a dopamine- and cyclic AMP-regulated neuronal phosphoprotein. J. Neurosci. 8: 508-517.

Kurihara, T., M. E. Ehrlich, J. Horiuchi, T. Nasu, and P. Greengard (1989) ARPP-21, a cyclic AMP-regulated phosphoprotein enriched in dopamine-innervated brain regions. II. Molecular cloning and nuclcotide sequence. J. Neurosci. 9: 3638-3644.

Matsuo, M., C. H. Huang, and L. C. Huang (1978) Evidence for an essential arginine recognition site on adenosine $3^{\prime}: 5^{\prime}$-cyclic monophosphate-dependent protein kinase of rabbit skeletal muscle. Biochem. J. 173: 441-447.

Nestler, E., and P. Greengard (1984) Protein Phosphorylation in the Nervous System, Wiley, New York.

Ouimet, C. C., P. E. Miller, H. C. Hemmings, Jr., S. I. Walaas, and P. Greengard (1984) DARPP-32, a dopamine- and 3':5'-monophosphate-regulated phosphoprotein enriched in dopamine-innervated brain regions. III. Immunocytochemical localization. J. Neurosci. 4: 111-124.

Ouimet, C. C., H. C. Hemmings, Jr., and P. Greengard (1989) ARPP21, a cyclic AMP-regulated phosphoprotein enriched in dopamineinnervated brain regions. II. Immunocytochemical localization in rat brain. J. Neurosci. 9: 865-875.

Small, D., P. Y. Chou, and G. D. Fasman (1977) Occurrence of phosphorylated residues in predicted beta-turns: Implications for betaturn participation in control mechanisms. Biochem. Biophys. Res. Commun. 79: 341-346.

Stone, K. L., and K. R. Williams (1986) High-performance liquid chromatographic peptide mapping and amino acid analysis in the subnanomole range. J. Chromatogr. 359: 203-212.

Tung, J.-S., and C. A. Knight (1972) Relative importance of some factors affecting the electrophoretic migration of proteins in sodium dodecyl sulfate-polyacrylamide gels. Anal. Biochem. 48: 153-163.

Walaas, S. I., and P. Greengard (1984) DARPP-32, a dopamine- and $3^{\prime}: 5^{\prime}$-monophosphate-regulated phosphoprotein enriched in dopamine-innervated brain regions. I. Regional and cellular distribution in rat brain. J. Neurosci. 4: 84-98.

Walaas, S. I., A. C. Nairn, and P. Greengard (1983) Regional distribution of calcium- and cyclic AMP-regulated protein phosphorylation systems in mammalian brain. II. Soluble systems. J. Neurosci. 3. 302-311.

Williams, K. R., H. C. Hemmings, Jr., M. B. LoPresti, W. H. Konigsberg, and P. Greengard (1986) DARPP-32, a dopamine- and cyclic AMP-regulated neuronal phosphoprotein: Primary structure and homology with protein phosphatase inhibitor-1. J. Biol. Chem. 261: 1890-1903.

Wold, F. (1984) Acetylated N-terminals in proteins: A perennial enigma. Trends Biochem. 9: 256-257.

Yoshida, A., and M. Lin (1972) $\mathrm{NH}_{2}$-terminal formylmethionine- and $\mathrm{NH}_{2}$-terminal methionine-cleaving enzymes in rabbits. J. Biol. Chem. 247: 952-957. 